\title{
Frequent homogeneous HER-2 amplification in primary and metastatic adenocarcinoma of the esophagus
}

\author{
Uta Reichelt $^{1}$, Peer Duesedau ${ }^{1}$, Maria Ch Tsourlakis ${ }^{1}$, Alexander Quaas ${ }^{1}$, Björn C Link ${ }^{2}$, \\ Paulus G Schurr ${ }^{2}$, Jussuf T Kaifi ${ }^{2}$, Stephanie J Gros ${ }^{2}$, Emre F Yekebas ${ }^{2}$, Andreas Marx ${ }^{1}$, \\ Ronald Simon ${ }^{1}$, Jakob R Izbicki ${ }^{2}$ and Guido Sauter ${ }^{1}$ \\ ${ }^{1}$ Department of Pathology, University Medical Center Hamburg-Eppendorf, University of Hamburg, \\ Hamburg, Germany and ${ }^{2}$ Department of General-, Visceral and Thoracic Surgery, University Medical Center \\ Hamburg-Eppendorf, Hamburg, Germany
}

\begin{abstract}
HER-2 is the target for antibody based treatment of breast cancer (Herceptin ${ }^{\circledR}$ ). In order to evaluate the potential role of such a treatment in esophageal cancers, HER-2 amplification and overexpression was investigated in primary and metastatic cancers of the esophagus. A tissue microarray was constructed from 255 primary esophageal cancers (110 adenocarcinomas and 145 squamous cell carcinomas), 89 nodal and 33 distant metastases. Slides were analyzed by immunohistochemistry (HercepTest ${ }^{\mathrm{TM}}$; DAKO) and fluorescence in situ hybridization (FISH; PathVysion ${ }^{\mathrm{TM}}$; Vysis-Abbott) for HER-2 amplification and overexpression. Amplification was seen in $16 / 110(15 \%)$ adenocarcinomas and in 7/145 (5\%) squamous cell carcinomas. There was a strong association between $H E R-2$ amplification and overexpression, especially in adenocarcinomas $(P<0.0001, \log$ rank). There was a $100 \%$ concordance of the HER-2 results in primary tumor and corresponding metastases in 84 analyzed pairs. Amplification was typically high-level with more than 10-15 HER-2 copies per tumor cell. Amplification was unrelated to survival, grading, pT, pN, pM or UICC stage. We conclude that esophageal adenocarcinomas belong to those cancer types with relevant frequency high-level HER-2 gene amplification clinical trials or individual case studies investigating the response of metastatic HER-2-positive esophageal cancers to Herceptin ${ }^{\circledR}$ should be undertaken. The strong concordance of the HER-2 status in primary and metastatic cancers argues for a possible response of metastases from patients with HER-2-positive primary tumors to Herceptin ${ }^{\mathbb{R}}$.

Modern Pathology (2007) 20, 120-129. doi:10.1038/modpathol.3800712; published online 24 November 2006
\end{abstract}

Keywords: HER-2 amplification and overexpression; primary and metastatic esophageal carcinomas; tissue microarray

The HER-2 oncogene is involved in the development of numerous types of human cancer and has been intensely evaluated as a therapeutic target. ${ }^{1-3}$ HER-2 gene amplification and protein overexpression occurs in about $20 \%$ of breast cancers ${ }^{4}$ and is linked to poor prognosis within these tumors. ${ }^{5}$ Even more importantly, HER-2 is the target of an antibody based therapy (trastuzumab; Herceptin ${ }^{\mathbb{R}}$ ), which is routinely used in metastatic HER-2-positive breast cancer. $^{6-8}$ More recently, adjuvant trastuzumab application was also shown to be dramatically effective in HER-2-positive breast cancer patients. ${ }^{9}$

Correspondence: Dr G Sauter, MD, Institute of Pathology, University Medical Center Hamburg-Eppendorf, Martinistrasse 52, 20246 Hamburg, Germany.

E-mail: g.sauter@uke.uni-hamburg.de

Received 8 May 2006; revised and accepted 2 August 2006; published online 24 November 2006
Remarkably, several studies have suggested considerable heterogeneity between primary breast cancer and their metastases suggesting that the HER-2 status of the metastases rather than the primary tumor findings may determine the effect of Herceptin ${ }^{\circledR}$ therapy. ${ }^{10,11}$

The potential benefit of trastuzumab in other tumor entities is largely unknown. HER-2 positivity has been described in most human tumor types but with a highly variable frequency. ${ }^{12-15}$ This especially applies for immunohistochemical (IHC) studies where different reagents and definitions of positivity resulted in an extremely wide range of HER-2 positivity in almost all tumor types. Despite of this, there is evidence for a possible response of HER2-positive nonbreast cancers to trastuzumab. ${ }^{16-18}$ Applying Herceptin ${ }^{\circledR}$ as additional treatment option would be of particular interest in tumors with a notoriously poor prognosis such as esophageal 
cancer. Several studies indeed suggested that HER-2 amplification/overexpression may be relevant for these tumor entities. HER-2 overexpression was reported in $0-83 \%$ of esophageal cancer, with a tendency towards higher rates of positivity in adenocarcinoma $(10-83 \%)^{19-34}$ compared to squamous cell carcinomas (0-56\%). ${ }^{31,32,35-40}$ A similar variability was observed in amplification analyses. Different methods for analysis (Southern blot or FISH) and definitions of amplification have resulted in amplification frequencies ranging from $15-100 \%$ in adenocarcinomas ${ }^{19-22,41-43}$ and from 0 to $25 \%$ in squamous cell carcinomas of the esophagus. ${ }^{31,35,39,44,45}$

In an attempt to clarify the significance of HER-2 gene amplifications in esophageal cancers and their metastases, FDA (US Food and Drug Administration) approved methods and scoring criteria for IHC (HercepTest ${ }^{\mathrm{TM}}$; DAKO) and fluorescent in situ hybridization (PathVysion $^{\mathrm{TM}}$; Vysis-Abbott) were used in this study. In order to obtain most reliable data, a tissue microarray was utilized. ${ }^{46}$ With this method, 255 primary tumors and 112 corresponding metastases could be analyzed on one slide on one day in one set of reagents thus allowing maximal assay standardization. Our data suggest an important role of HER-2 in esophageal adenocarcinoma.

\section{Subjects and methods}

\section{Patients}

A consecutive set of 292 patients operated for esophageal cancer between 1992 and 2004 of the University Medical Center Hamburg-Eppendorf was analyzed including 129 adenocarcinomas and 163 squamous cell carcinomas from 228 males and 64 females, ranging in age from 34 to 92 years (median 62 years). All patients had curative en bloc esophageal resection and radical lymph node dissection. Continuous follow-up data were recorded from 287 patients (125 adenocarcinomas, 162 squamous cell carcinomas). For each patient who died during the follow-up period, the cause of death was determined as cancer-related or not cancer-related. Patients that died within 1 month after surgery were excluded as perioperative failures. Four patients with adenocarcinoma and one with squamous cell carcinoma were lost to follow-up. Median follow-up time for all patients was 23 months (95\% CI: 18.427.6). All tumors were reclassified for this study according to the WHO 2000 classification. ${ }^{47}$

\section{Tissue Microarray Construction}

Tissue samples were fixed in $4 \%$ buffered formalin, paraffin embedded, and used for tissue microarray construction as described. ${ }^{46}$ Haematoxylin-eosin stained sections were made from selected primary tumor blocks (donor blocks) to define representative tumor regions. Tissue cylinders $(0.6 \mathrm{~mm}$ in diameter) were then punched from that region of the donor block using a homemade semiautomated tissue arrayer. Control samples included normal esophagus mucosa $(n=10)$, endometrium $(n=2)$, skin $(n=2)$, skeletal muscle $(n=2)$, heart muscle $(n=2)$, colon mucosa $(n=2)$, lung $(n=2)$, lymph node $(n=2)$, prostate $(n=2)$ and kidney $(n=2)$. An overview of the complete tissue microarray with a total of 510 tissue samples is shown in Figure 1a, a single tissue spot of each adenocarcinoma and squamous cell carcinoma stained with haematoxylin-eosin is shown in Figure 1b and c. Three $\mu \mathrm{m}$ sections were made by use of the Paraffin Sectioning Aid System (Instrumentics, Hackensack, NJ, USA). Consecutive sections were used for fluorescence in situ hybridization (FISH) and IHC analysis.

\section{Fluorescence In Situ Hybridization}

For proteolytic slide pretreatment a commercial kit was utilized (Paraffin pretreatment reagent kit, Vysis, Downers Grove, IL, USA). Spectrum-Orangelabeled HER-2 probes were used together with Spectrum-Green-labeled centromer 17 reference probes (PathVysion ${ }^{\mathrm{TM}}$, Vysis-Abbott). Before hybridization, sections were deparaffinized, air dried, dehydrated and then denaturized for $5 \mathrm{~min}$ at $74^{\circ} \mathrm{C}$ in $70 \%$ formamide-2 X SSC solution. After overnight hybridization at $37^{\circ} \mathrm{C}$ in a humid chamber, slides were washed and counterstained with $0.2 \mu \mathrm{M}$ DAPI in an antifade solution. The mean numbers of HER-2 and centromer 17 signals were estimated for each tumor sample as described before. ${ }^{48,49}$ Our criteria for HER-2 gene amplification were a HER-2/centromer 17 signal ratio $\geq 2$. Low-level amplification ratio was defined as $H E R$-2/centromer 17 at $\geq 2$ to $<3$, high-level amplification was defined as a HER$2 /$ centromer 17 ratio of $\geq 3$.

\section{Immunohistochemistry}

The HercepTest ${ }^{\mathrm{TM}}$ (DAKO, Glostrup, Denmark) was used according to the protocol of the manufacturer. Antigen retrieval of the deparaffinized tissue sections was performed in a waterbath at $95^{\circ}-99^{\circ} \mathrm{C}$ for $50 \mathrm{~min}$ followed by peroxidase blocking and incubation with the prediluted primary antibody. Cell line test slides provided by the manufacturer were used as positive and negative controls. Immunostaining was scored by one pathologist (UR), following a four-step scale $(0,1+, 2+, 3+)$ according the manufacturer's directions.

\section{Statistical Analysis}

Contingency table analysis and Fisher's exact test were used to study the relationship between HER-2 alterations and categorical parameters. Survival 

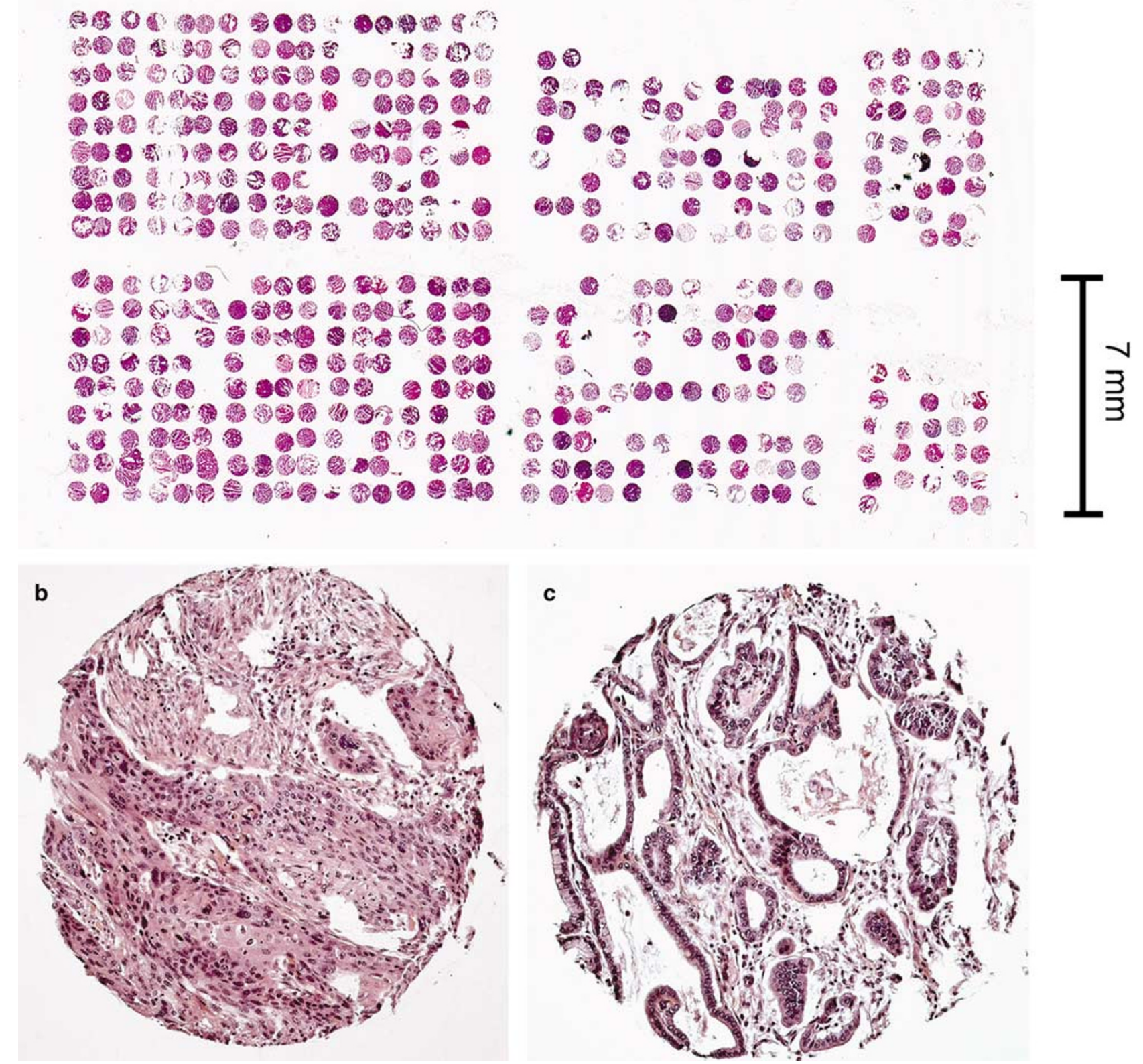

Figure 1 Esophageal cancer array. (a) Complete esophageal cancer array, stained with hematoxylin-eosin, consisting of one paraffin block $(25 \times 30 \mathrm{~mm})$. (b) Example of a single hematoxylin-eosin stained tissue spot of an esophagus squamous cell carcinoma (magnification $\times 100$ ). (c) Example of a single hematoxylin-eosin stained tissue spot of an esophageal adenocarcinoma (magnification $\times 100)$. (d) Example of a single tissue spot of an esophageal adenocarcinoma showing strong $(3+)$ HER-2 protein expression (magnification $\times 100$ ). (e) Example of a single tissue spot of an esophageal adenocarcinoma showing HER-2-negative immunohistochemistry (magnification $\times 100$ ). (f) Example of a single HER-2-amplified tissue spot of an esophageal adenocarcinoma (magnification $\times 1000)$. (g) Example of a single HER-2-nonamplified tissue spot of an esophagus adenocarcinoma (magnification $\times 1000$ ).

curves were plotted according to Kaplan-Meier. A log rank test was applied to examine the relationship between molecular or histological data and tumor-specific survival. Tumor-specific survival was scheduled as our clinical end point. Analysis was performed using the SPSS statistical software package for Windows (version 13.0, SPSS Inc., Chicago, IL, USA).

\section{Results}

\section{Clinical Data}

Among all 251 patients with available follow-up data (four adenocarcinomas were lost to follow-up) there were 134 tumor-related deaths (53\%), 27 perioperative deaths $(11 \%)$ which were excluded 

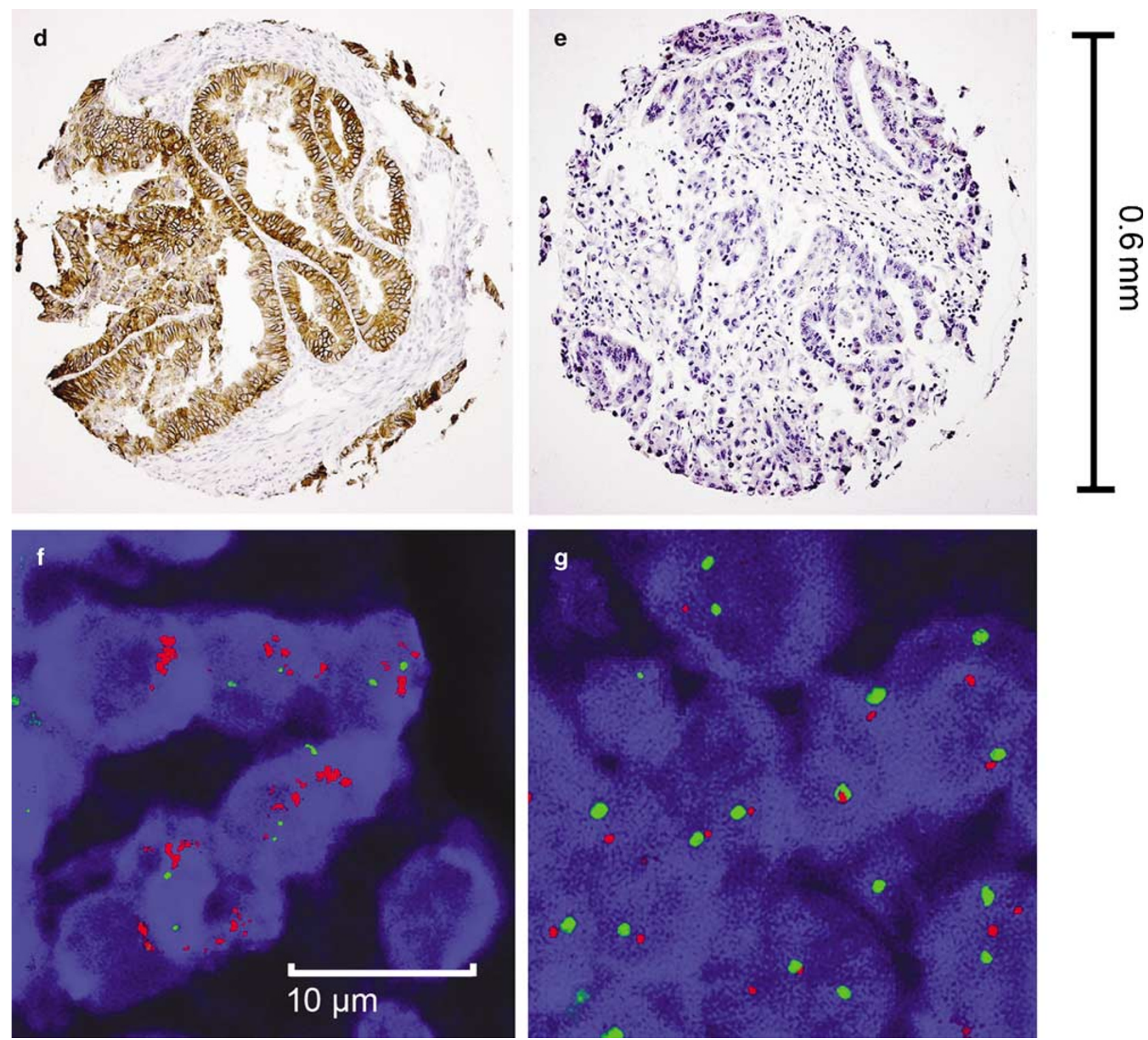

Figure 1 Continued.

from survival analysis and 23 tumor-unrelated deaths $(9 \%)$. The remaining 67 patients were alive at the time of their last clinical control. This includes $54(22 \%)$ disease-free patients. Average disease-specific survival was 25 months (95\% CI: 18.7-31.3) for adenocarcinomas and 19 months (95\% CI: 14-24) for squamous cell carcinomas. pT $(P<0.0001$, log rank; Figure 2a), $\mathrm{pN}(P<0.0001$, log rank), pM $(P<0.0001$, log rank $)$ and UICC stage $(P<0.0001$, log rank $)$, but not histologic grade and tumor type were significantly related to survival time.

\section{Technical Aspects of HER-2 Analysis}

A total of 255 primary tumors, 89 nodal and 33 distant metastases were interpretable by FISH
(79\% of all samples). The remaining 102 samples were noninformative because of absence of tissue on the tissue microarray, lack of unequivocal tumor cells in the arrayed samples or insufficient hybridization $(n=377)$. Only one tissue microarray section was hybridized. No attempts were made to increase the number of informative cases by additional experiments under different conditions because the absolute number of interpretable cases was considered large enough for the purpose of this study. Examples of interpretable HER-2 amplified and nonamplified cancers are shown in Figure if and g. For IHC, 378 of our samples were interpretable while 101 were not interpretable due to the absence of tissue on the tissue microarray or a lack of unequivocal tumor cells in the arrayed samples. Examples of interpretable tumor tissue samples of positive and negative HER-2 IHC are shown in 

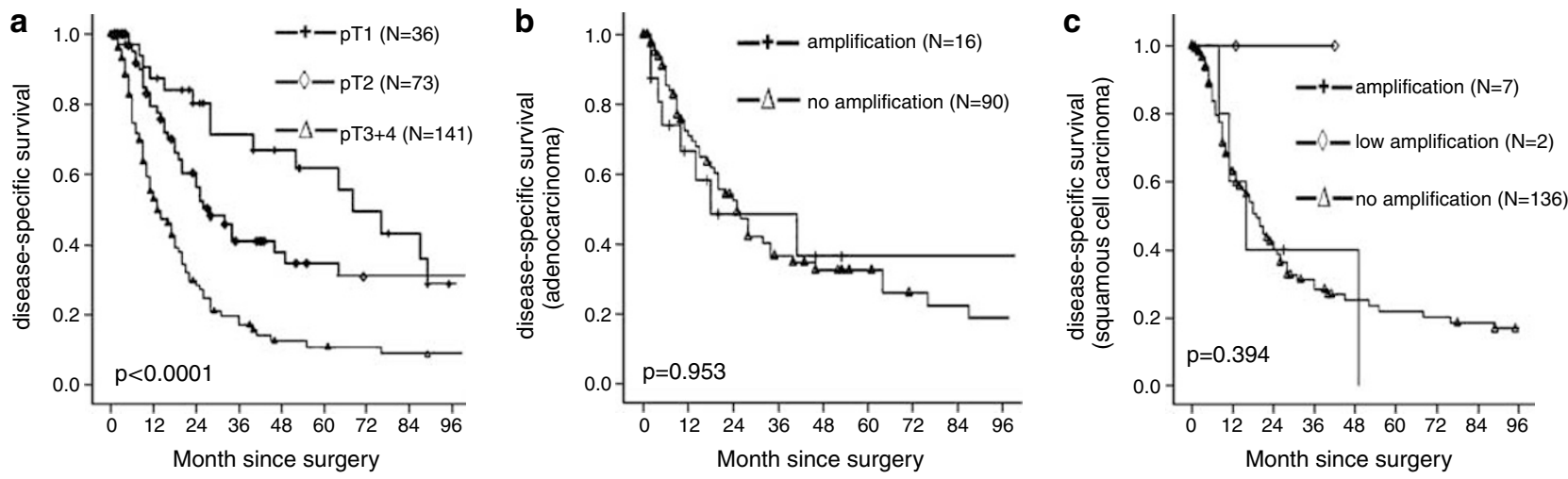

Figure 2 (a) Kaplan-Meier curve for disease-specific survival and pT-stage in esophageal cancer. $P$-values were calculated using log rank test. (b) Kaplan-Meier curve for disease-specific survival and HER-2 amplification in esophageal adenocarcinomas. $P$-values were calculated using log rank test. (c) Kaplan-Meier curve for disease-specific survival and HER-2 amplification in esophageal squamous cell carcinomas. $P$-values were calculated using log rank test.

Table 1a HER-2 amplification and overexpression in primary adenocarcinoma (subgroup analysis)

\begin{tabular}{|c|c|c|c|c|c|c|c|c|c|c|c|}
\hline & \multicolumn{5}{|c|}{ FISH } & \multicolumn{6}{|c|}{ Immunohistochemistry } \\
\hline & $\mathrm{N}$ & Ratio $\leq 2(\%)$ & Ratio $\geq 2$ to $<3(\%)$ & Ratio $>3(\%)$ & $\mathrm{P}$-value & $\mathrm{N}$ & Neg. (\%) & $+1(\%)$ & $+2(\%)$ & $+3(\%)$ & $\mathrm{P}$-value \\
\hline \multicolumn{12}{|l|}{$p T$} \\
\hline 1 & 17 & 77 & 0 & 23 & & 18 & 50 & 28 & 11 & 11 & \\
\hline 2 & 41 & 90 & 0 & 10 & & 42 & 71 & 19 & 5 & 5 & \\
\hline $3+4$ & 53 & 85 & 0 & 15 & 0.351 & 53 & 60 & 26 & 6 & 8 & 0.702 \\
\hline \multicolumn{12}{|l|}{ Grade } \\
\hline 1 & 0 & 0 & 0 & 0 & & 0 & 0 & 0 & 0 & 0 & \\
\hline 2 & 41 & 80 & 0 & 20 & & 41 & 56 & 24 & 10 & 10 & \\
\hline 3 & 68 & 88 & 0 & 12 & 0.278 & 71 & 68 & 23 & 4 & 5 & 0.445 \\
\hline \multicolumn{12}{|l|}{$p N$} \\
\hline 0 & 27 & 78 & 0 & 22 & & 28 & 54 & 21 & 14 & 11 & \\
\hline $1-3$ & 82 & 88 & 0 & 12 & 0.219 & 84 & 67 & 24 & 4 & 6 & 0.158 \\
\hline \multicolumn{12}{|l|}{$R$} \\
\hline 0 & 87 & 86 & 0 & 14 & & 90 & 63 & 23 & 7 & 7 & \\
\hline 1 & 12 & 83 & 0 & 17 & & 12 & 67 & 17 & 8 & 8 & \\
\hline 2 & 8 & 88 & 0 & 12 & 0.870 & 8 & 63 & 38 & 0 & 0 & 0.965 \\
\hline \multicolumn{12}{|l|}{$p M$} \\
\hline 0 & 80 & 86 & 0 & 14 & & 82 & 62 & 24 & 6 & 7 & \\
\hline $1+2$ & 30 & 83 & 0 & 17 & 0.763 & 31 & 65 & 23 & 7 & 7 & 1.000 \\
\hline \multicolumn{12}{|c|}{ UICC status } \\
\hline 1 & 19 & 79 & 0 & 21 & & 20 & 50 & 25 & 15 & 10 & \\
\hline 2 & 32 & 91 & 0 & 9 & & 33 & 73 & 18 & 3 & 6 & \\
\hline 3 & 30 & 83 & 0 & 17 & & 30 & 53 & 33 & 3 & 10 & \\
\hline 4 & 29 & 86 & 0 & 14 & 0.671 & 30 & 70 & 20 & 7 & 3 & 0.542 \\
\hline
\end{tabular}

$P$-values were calculated using Fisher's exact test.

Figure 1d and e. Both FISH and IHC were interpretable on the same tissue spot in 110 primary adenocarcinomas and in 144 primary squamous cell carcinomas. All control samples were always HER-2 negative both by IHC and FISH.

\section{HER-2 in Primary Tumors}

Frequency and type of HER-2 alterations varied considerably between adenocarcinomas and squamous cell carcinomas (Tables 1a and b). In adenocarcinomas, high-level amplification (ratio HER-2/centromer $17 \geq 3)$ was markedly more frequent $(15 \% ; 16 /$ $110)$ than in squamous cell carcinomas $(5 \% ; 7 / 145$; $P<0.009$, Fisher's exact test). High-level amplifications were strongly associated with protein overexpression in both tumor types (adenocarcinoma: $P<0.0001$; squamous cell carcinoma: $P=0.002$, Fisher's exact test). Lower-level amplifications, defined as ratio HER-2/centromer 17 between 2 and 3 , were not observed in adenocarcinomas. 
Table 1b HER-2 amplification and overexpression in primary squamous cell carcinoma (subgroup analysis)

\begin{tabular}{|c|c|c|c|c|c|c|c|c|c|c|c|}
\hline & \multicolumn{5}{|c|}{ FISH } & \multicolumn{6}{|c|}{ Immunohistochemistry } \\
\hline & $\mathrm{N}$ & Ratio < $2(\%)$ & Ratio $\geq 2$ to $<3(\%)$ & Ratio $\geq 3(\%)$ & $\mathrm{P}$-value & $\mathrm{N}$ & Neg. $(\%)$ & $+1(\%)$ & $+2(\%)$ & $+3(\%)$ & $\mathrm{P}$-value \\
\hline \multicolumn{12}{|l|}{$p T$} \\
\hline 1 & 19 & 100 & 0 & 0 & & 19 & 68 & 16 & 16 & 0 & \\
\hline 2 & 34 & 82 & 3 & 15 & & 34 & 65 & 24 & 6 & 6 & \\
\hline $3+4$ & 91 & 97 & 1 & 2 & 0.035 & 92 & 70 & 27 & 2 & 1 & 0.130 \\
\hline \multicolumn{12}{|l|}{ Grade } \\
\hline 1 & 4 & 100 & 0 & 0 & & 4 & 75 & 25 & 0 & 0 & \\
\hline 2 & 98 & 92 & 2 & 6 & & 99 & 70 & 23 & 6 & 1 & \\
\hline 3 & 42 & 98 & 0 & 2 & 0.771 & 42 & 64 & 29 & 2 & 5 & 0.632 \\
\hline \multicolumn{12}{|l|}{$p N$} \\
\hline 0 & 55 & 91 & 2 & 7 & & 55 & 71 & 20 & 7 & 2 & \\
\hline $1-3$ & 90 & 96 & 1.1 & 3 & 0.509 & 91 & 67 & 28 & 3 & 2 & 0.563 \\
\hline \multicolumn{12}{|l|}{$R$} \\
\hline 0 & 115 & 94 & 0 & 6 & & 116 & 70 & 22 & 6 & 3 & \\
\hline 1 & 24 & 96 & 4 & 0 & & 24 & 59 & 38 & 4 & 0 & \\
\hline 2 & 6 & 83 & 17 & 0 & 0.034 & 6 & 83 & 17 & 0 & 0 & 0.739 \\
\hline \multicolumn{12}{|l|}{$p M$} \\
\hline 0 & 125 & 94 & 1 & 5 & & 126 & 71 & 23 & 5 & 2 & \\
\hline $1+2$ & 19 & 90 & 5 & 5 & 0.285 & 19 & 53 & 37 & 5 & 5 & 0.188 \\
\hline \multicolumn{12}{|c|}{ UICC status } \\
\hline 1 & 15 & 100 & 0 & 0 & & 15 & 67 & 20 & 13 & 0 & \\
\hline 2 & 54 & 91 & 2 & 7 & & 54 & 70 & 20 & 6 & 4 & \\
\hline 3 & 49 & 98 & 0 & 2 & & 50 & 72 & 26 & 3 & 0 & \\
\hline 4 & 26 & 89 & 4 & 8 & 0.474 & 26 & 58 & 35 & 4 & 4 & 0.505 \\
\hline
\end{tabular}

$P$-values were calculated using Fisher's exact test.

The vast majority of amplified adenocarcinomas $(14 / 16 ; 88 \%)$ showed a strong HER-2 protein expression $(2+/ 3+)$ on corresponding IHC stained sections. One of $94(1 \%)$ nonamplified adenocarcinomas (ratio $<2.0$ ) showed a positive HER-2 protein expression $(2+)$ and two highly amplified tumors showed no (0) or just a low positive HER-2 protein expression $(1+)$ (Figure 3a).

HER-2 amplification was less frequent in squamous cell carcinoma than in adenocarcinoma. In these tumors, the average HER-2 gene copy number per amplified tumor cells (3.2; 95\% CI: 2.529-3.885) was significantly lower than in adenocarcinomas (6.4; 95\% CI: 3.838-8.944; $P=0.008$; ANOVA). Most $2+$ tumors (5/7) and one of three $3+$ tumors had no HER-2 amplification by FISH. Accordingly, the relationship with HER-2 protein overexpression was much less stringent than in adenocarcinoma but still significant $(P=0.002$, log rank; Figure $3 b)$.

Both HER-2 amplification and overexpression were generally unrelated to $\mathrm{pT}, \mathrm{pN}, \mathrm{pM}$, grade, UICC-status and resection margin (Tables 1a and b). This holds true for all tumors as well as for the subgroups of adenocarcinomas and squamous cell carcinomas, with two exceptions in squamous cell carcinomas. Here, an inverse correlation was found between amplification and resection margin $(P=0.034$, Fisher's exact test $)$ and a positive association between $\mathrm{pT}$ and HER-2 amplification $(P=0.035$, Fisher's exact test, Table $1 \mathrm{~b})$.
No correlation was observed between survival and HER-2 amplification (Figure $2 \mathrm{~b}$ and $\mathrm{c}$ ) or overexpression (data not shown), neither in adenocarcinoma $(P=0.953$, Fisher's exact test $)$ nor in squamous cell carcinoma ( $P=0.394$, Fisher's exact test).

\section{HER-2 in Metastases}

HER-2 status of lymph nodes and distant metastases was strongly correlated to the HER-2 findings in the respective primary tumors. For FISH, the findings in lymph node metastases corresponded exactly to the primary tumor data in all 84 (adenocarcinoma: $n=43$; squamous cell carcinoma: $n=41$ ) successfully analyzed pairs $(100 \% ; P<0.0001$, Fisher's exact test) and in distant metastasis in all 30 (adenocarcinoma: $n=21$; squamous cell carcinoma: $n=9$ ) analyzed pairs. These pairs included 16 patients (adenocarcinoma: $n=11$; squamous cell carcinoma: $n=5$ ) from which the primary tumor, the corresponding lymph node metastasis and the distant metastasis could be analyzed, all with $100 \%$ concordance.

The concordance between primary tumors and lymph node metastasis was still good but less perfect for IHC. In adenocarcinomas a complete concordance in the scoring results was seen in 23 (54\%, $P=0.001$, Fisher's exact test), in squamous cell carcinomas in $20(50 \%, P=0.036$, Fisher's exact 

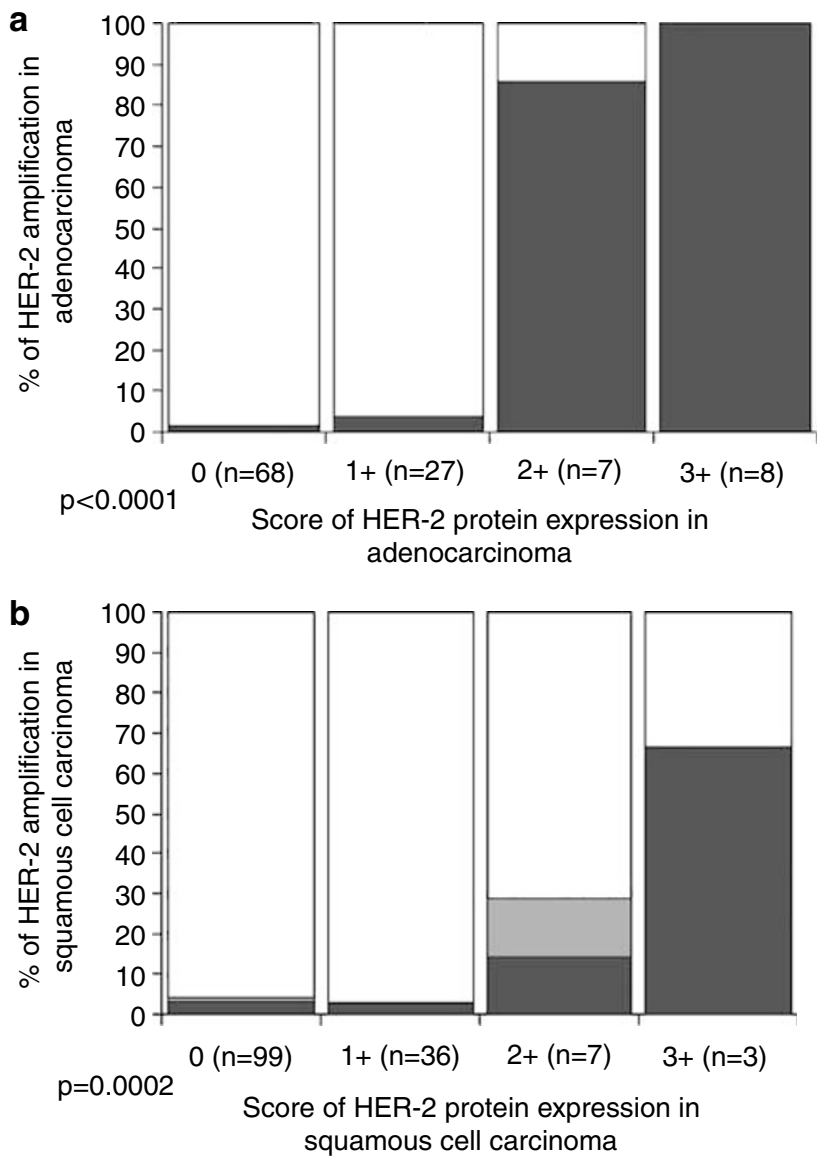

Figure 3 (a) HER-2 status in primary tumor samples. Comparison of HER-2 expression determined by IHC and HER-2 amplification determined by FISH in esophageal adenocarcinomas. Black area $=$ percentage of tumors with high-level HER-2 amplification; white area $=$ percentage of tumors with no HER-2 amplification. (b) HER-2 status in primary tumor samples. Comparison of HER-2 expression determined by IHC and HER-2 amplification determined by FISH in esophagus squamous cell carcinomas. Black area $=$ percentage of tumors with high-level HER-2 amplification; gray area = percentage of tumors with low-level HER-2 amplification; white area = percentage of tumors with no HER-2 amplification.

test) of pairs. A difference of only one point was seen in $18(42 \%)$ adenocarcinomas and in $19(48 \%)$ squamous cell carcinomas while a difference of two or more points occurred in only two $(5 \%)$ adenocarcinomas and in one $(2 \%)$ squamous cell carcinoma.

\section{Discussion}

Fundamental differences in the role of HER-2 amplification/overexpression were found between adenocarcinomas and squamous cell carcinomas of the esophagus in this study. The findings in adenocarcinomas were very similar to breast cancer, the best examined cancer type for HER-2 alterations so far. ${ }^{4,50}$ Strong overexpression was seen in $13 \%$ of cases and almost all of them had high-level HER-2 amplification with greater than 10-15 HER-2 copies per cell. It appears possible, that the one adenocarcinoma with overexpression $(2+)$ in the absence of amplification and the two cases with amplification in the absence of overexpression may represent technical errors of IHC based on fixation variability in routinely processed clinical samples. ${ }^{51}$ The same reasons may apply for discrepant IHC results between primary tumors and metastases. It is well known, that prolonged formalin fixation can disturb immunohistochemical detectability of HER-2 protein while insufficient formalin fixation with consecutive tissue exposure to ethanol during technical processing can lead to false positive HER-2 IHC. ${ }^{52-54}$

Considering the encouraging results of clinical trials in breast cancer, it could be speculated that Herceptin ${ }^{\circledR}$ might also represent a possible option for HER-2 amplified esophageal adenocarcinomas. The only published clinical Herceptin ${ }^{\circledR}$ trial for esophagus cancer patients was a phase I study testing 30 patients, including six patients with HER2 amplified tumors. In this study, only local tumor response was studied after combined radiation, paclitaxel, cisplatin, Herceptin ${ }^{\mathbb{B}}$ therapy. Although many responders were reported, the possible contribution of Herceptin ${ }^{\mathbb{R}}$ cannot be appreciated in this study. ${ }^{34}$ Clinical trials or individual case studies investigating the response of HER-2 amplified metastatic esophageal cancers to Herceptin ${ }^{\circledR}$ are clearly needed.

Remarkably, HER-2 results in squamous cell carcinoma were much less unequivocal. Moderate expression $(2+)$ according to the FDA approved IHC criteria were more frequently seen than $3+$ positivity. Accordantly the association of IHC positivity with amplification was less strong than in adenocarcinoma. These data fit well with observations in other squamous carcinoma types. HER-2 amplification is less frequent in squamous cell carcinoma of the lung than in adenocarcinoma of the lung ${ }^{55-58}$ and rather infrequent in most prevalent squamous cell carcinomas like head and neck, ${ }^{59,60}$ skin $^{61}$ or cervical carcinomas. ${ }^{62,63}$

The current use of molecular diagnostics for targeted cancer therapy is depending on the assumption that all metastases will show the same target gene alteration as observed in the primary tumor. To investigate this issue, nodal and distant metastases of our cancers were also included in our tissue microarray. Remarkably, no discrepant finding was observed in any of our 84 patients for which primary tumor and its metastases could be analyzed for HER-2 amplification. This fits well to the results of a previous FISH study which failed to find discrepant HER-2 results in eight primary esophageal cancers and corresponding lymph node metastasis. ${ }^{43}$ Importantly, this perfect concordance could only be seen after a reanalysis of 10 cases initially discrepant data. All these tumors had a borderline finding (ratio HER-2/centromer 17 of 1.8-3.0) they were initially considered amplified in one sample 
(primary tumor or metastasis) and nonamplified in the other sample (metastasis or primary tumor). A direct comparison of the HER-2 findings in these cases including large section analyses revealed no significant differences between primary and metastatic tumors, however. The strong concordance of the HER-2 status in primary and metastatic carcinomas $(P<0.0001$, Fisher's exact test $)$ provides further support for a possible application of Herceptin ${ }^{\circledR}$, especially in highly amplified adenocarcinomas. Occasional discrepancies in the IHC results are most likely due to the inherent shortcoming of the IHC dealing with tissues that were processed in a nonstandardized way.

High-quality clinical and experimental data were used in this study. The strong association between clinical data and patient survival provides a perfect indirect validation for quality of our clinical data. The validity of our (FDA approved) assays is indirectly corroborated by the very strong concordance of FISH and IHC data. In spite of this clean data set, no clear association was found between HER-2 alteration and clinicopathological parameters. In particular, there was no association between HER-2 alteration and patient prognosis. This result is in line with the results of most previous studies. ${ }^{28,31,32,36}$ The existence of several published papers reporting associations of HER-2 amplification/overexpression with both poor $^{24,35,42}$ and improved prognosis ${ }^{25,30}$ also rather argue against an important prognostic role of HER-2 in esophageal cancers. The general absence of an association of HER-2 amplification or overexpression with clinical parameters of malignancy is in line with previous studies. ${ }^{19,24,31,37}$ We cannot offer a biologic explanation for the observed association between HER-2 status and negative resection margins or pT2 stage in squamous cell carcinoma. It cannot be excluded that these results represent statistical artefacts in a study patterning a high number of statistical analyses.

In conclusion, a thorough analysis of 255 esophageal cancers using FDA approved reagents showed a frequent amplification of $\mathrm{HER}-2$ in esophageal adenocarcinoma $(15 \%)$ and a strong concordance of HER-2 status in primary and metastatic cancer $(P<0.0001)$. These results should encourage clinical trials or individual case studies using Herceptin ${ }^{\circledR}$ in metastatic adenocarcinomas of the esophagus.

\section{References}

1 Hynes NE, Lane HA. ERBB receptors and cancer: the complexity of targeted inhibitors. Nat Rev Cancer 2005;5:341-354.

2 Normanno N, Bianco C, Strizzi L, et al. The ErbB receptors and their ligands in cancer: an overview. Curr Drug Targets 2005;6:243-257.

3 Rabindran SK. Antitumor activity of HER-2 inhibitors. Cancer Lett 2005;227:9-23.
4 Zhang D, Salto-Tellez M, Do E, et al. Evaluation of HER-2/neu oncogene status in breast tumors on tissue microarrays. Hum Pathol 2003;34:362-368.

5 Slamon DJ, Clark GM, Wong SG, et al. Human breast cancer: correlation of relapse and survival with amplification of the HER-2/neu oncogene. Science 1987;235:177-182.

6 Baselga J, Tripathy D, Mendelsohn J, et al. Phase II study of weekly intravenous trastuzumab (Herceptin) in patients with HER2/neu-overexpressing metastatic breast cancer. Semin Oncol 1999;26:78-83.

7 Leyland-Jones B. Trastuzumab: hopes and realities. Lancet Oncol 2002;3:137-144.

8 Tripathy D, Slamon DJ, Cobleigh M, et al. Safety of treatment of metastatic breast cancer with trastuzumab beyond disease progression. J Clin Oncol 2004;22: 1063-1070.

9 Tuma RS. Trastuzumab trials steal show at ASCO meeting. J Natl Cancer Inst 2005;97:870-871.

$10 \mathrm{Xu}$ R, Perle MA, Inghirami G, et al. Amplification of Her-2/neu gene in Her-2/neu-overexpressing and-nonexpressing breast carcinomas and their synchronous benign, premalignant, and metastatic lesions detected by FISH in archival material. Mod Pathol 2002;15: 116-124.

11 Zidan J, Dashkovsky I, Stayerman C, et al. Comparison of HER-2 overexpression in primary breast cancer and metastatic sites and its effect on biological targeting therapy of metastatic disease. Br J Cancer 2005;93: $552-556$.

12 Ross JS, McKenna BJ. The HER-2/neu oncogene in tumors of the gastrointestinal tract. Cancer Invest 2001;19:554-568.

13 Allgayer H, Babic R, Gruetzner KU, et al. c-erbB-2 is of independent prognostic relevance in gastric cancer and is associated with the expression of tumorassociated protease systems. J Clin Oncol 2000;18: 2201-2209.

14 Safran H, Steinhoff M, Mangray S, et al. Overexpression of the HER-2/neu oncogene in pancreatic adenocarcinoma. Am J Clin Oncol 2001;24:496-499.

15 Endo K, Yoon BI, Pairojkul C, et al. ERBB-2 overexpression and cyclooxygenase-2 up-regulation in human cholangiocarcinoma and risk conditions. Hepatology 2002;36:439-450.

16 Langer CJ, Stephenson P, Thor A, et al. Trastuzumab in the treatment of advanced non-small-cell lung cancer: is there a role? Focus on Eastern Cooperative Oncology Group Study 2598. J Clin Oncol 2004;22: 1180-1187.

17 Kollmannsberger C, Pressler H, Mayer F, et al. Cisplatin-refractory, HER2/neu-expressing germ-cell cancer: induction of remission by the monoclonal antibody trastuzumab. Ann Oncol 1999;10:1393-1394.

18 Locati LD, Rinaldi G, Bossi P, et al. Herceptin plus chemotherapy in relapsed and/or metastatic salivary gland cancer. Oral Oncol 2005;41:97-98.

19 al-Kasspooles M, Moore JH, Orringer MB, et al. Amplification and over-expression of the EGFR and erbB-2 genes in human esophageal adenocarcinomas. Int J Cancer 1993;54:213-219.

20 Geddert $\mathrm{H}$, Zeriouh $\mathrm{M}$, Wolter $\mathrm{M}$, et al. Gene amplification and protein overexpression of c-erb-b2 in Barrett's carcinoma and its precursor lesions. Am J Clin Pathol 2002;118:60-66.

21 Walch A, Bink K, Gais P, et al. Evaluation of c-erbB-2 overexpression and Her-2/neu gene copy number 
heterogeneity in Barrett's adenocarcinoma. Anal Cell Pathol 2000;20:25-32.

22 Walch A, Specht K, Bink K, et al. Her-2/neu gene amplification, elevated mRNA expression, and protein overexpression in the metaplasia-dysplasia-adenocarcinoma sequence of Barrett's esophagus. Lab Invest 2001;81:791-801.

23 Jankowski J, Coghill G, Hopwood D, et al. Oncogenes and onco-suppressor gene in adenocarcinoma of the oesophagus. Gut 1992;33:1033-1038.

24 Flejou JF, Paraf F, Muzeau F, et al. Expression of c-erbB-2 oncogene product in Barrett's adenocarcinoma: pathological and prognostic correlations. J Clin Pathol 1994;47:23-26.

25 Nakamura T, Nekarda H, Hoelscher AH, et al. Prognostic value of DNA ploidy and c-erbB-2 oncoprotein overexpression in adenocarcinoma of Barrett's esophagus. Cancer 1994;73:1785-1794.

26 Hardwick RH, Shepherd NA, Moorghen M, et al. c-erbB-2 overexpression in the dysplasia/carcinoma sequence of Barrett's oesophagus. J Clin Pathol 1995; 48:129-132.

27 Kim R, Clarke MR, Melhem MF, et al. Expression of p53, PCNA, and C-erbB-2 in Barrett's metaplasia and adenocarcinoma. Dig Dis Sci 1997;42:2453-2462.

28 Polkowski W, van Sandick JW, Offerhaus GJ, et al. Prognostic value of Lauren classification and c-erbB-2 oncogene overexpression in adenocarcinoma of the esophagus and gastroesophageal junction. Ann Surg Oncol 1999;6:290-297.

29 Sauter ER, Keller SM, Erner S, et al. HER-2/neu: a differentiation marker in adenocarcinoma of the esophagus. Cancer Lett 1993;75:41-44.

30 Duhaylongsod FG, Gottfried MR, Iglehart JD, et al. The significance of c-erb B-2 and p53 immunoreactivity in patients with adenocarcinoma of the esophagus. Ann Surg 1995;221:677-683; discussion 683-684.

31 Friess H, Fukuda A, Tang WH, et al. Concomitant analysis of the epidermal growth factor receptor family in esophageal cancer: overexpression of epidermal growth factor receptor mRNA but not of c-erbB-2 and c-erbB-3. World J Surg 1999;23:1010-1018.

32 Hardwick RH, Barham CP, Ozua P, et al. Immunohistochemical detection of p53 and c-erbB-2 in oesophageal carcinoma; no correlation with prognosis. Eur J Surg Oncol 1997;23:30-35.

33 Trudgill NJ, Suvarna SK, Royds JA, et al. Cell cycle regulation in patients with intestinal metaplasia at the gastro-oesophageal junction. Mol Pathol 2003;56: $313-317$

34 Safran H, DiPetrillo T, Nadeem A, et al. Trastuzumab, paclitaxel, cisplatin, and radiation for adenocarcinoma of the esophagus: a phase I study. Cancer Invest 2004;22:670-677.

35 Mimura K, Kono K, Hanawa M, et al. Frequencies of HER-2/neu expression and gene amplification in patients with oesophageal squamous cell carcinoma. Br J Cancer 2005;92:1253-1260.

36 Akamatsu M, Matsumoto T, Oka K, et al. C-erbB-2 oncoprotein expression related to chemoradioresistance in esophageal squamous cell carcinoma. Int J Radiat Oncol Biol Phys 2003;57:1323-1327.

37 Lam KY, Tin L, Ma L. C-erbB-2 protein expression in oesophageal squamous epithelium from oesophageal squamous cell carcinomas, with special reference to histological grade of carcinoma and pre-invasive lesions. Eur J Surg Oncol 1998;24:431-435.
38 Suo Z, Holm R, Nesland JM. Squamous cell carcinomas, an immunohistochemical and ultrastructural study. Anticancer Res 1992;12:2025-2031.

39 Suo Z, Su W, Holm R, et al. Lack of expression of c-erbB-2 oncoprotein in human esophageal squamous cell carcinomas. Anticancer Res 1995;15:2797-2798.

40 Suwanagool P, Parichatikanond P, Maeda S. Expression of c-erbB-2 oncoprotein in primary human tumors: an immunohistochemistry study. Asian Pac J Allergy Immunol 1993;11:119-122.

41 Persons DL, Croughan WS, Borelli KA, et al. Interphase cytogenetics of esophageal adenocarcinoma and precursor lesions. Cancer Genet Cytogenet 1998;106: 11-17.

42 Brien TP, Odze RD, Sheehan CE, et al. HER-2/neu gene amplification by FISH predicts poor survival in Barrett's esophagus-associated adenocarcinoma. Hum Pathol 2000;31:35-39.

43 Walch AK, Zitzelsberger HF, Bink K, et al. Molecular genetic changes in metastatic primary Barrett's adenocarcinoma and related lymph node metastases: comparison with nonmetastatic Barrett's adenocarcinoma. Mod Pathol 2000;13:814-824.

44 Ikeda Y, Ozawa S, Ando N, et al. Meanings of c-erbB and int-2 amplification in superficial esophageal squamous cell carcinomas. Ann Thorac Surg 1996; 62:835-838.

45 Tanaka S, Mori M, Akiyoshi T, et al. Coexpression of Grb7 with epidermal growth factor receptor or Her2/ erbB2 in human advanced esophageal carcinoma. Cancer Res 1997;57:28-31.

46 Kononen J, Bubendorf L, Kallioniemi A, et al. Tissue microarrays for high-throughput molecular profiling of tumor specimens. Nat Med 1998;4:844-847.

47 Hamilton SR, Aaltonen LA (eds). World Health Organization Classification of Tumors: Pathology \& Genetics of Tumors of the Digestive System. Oxford University Press: New York, 2000.

48 Bubendorf L, Kononen J, Koivisto P, et al. Survey of gene amplifications during prostate cancer progression by high-throughout fluorescence in situ hybridization on tissue microarrays. Cancer Res 1999;59: 803-806.

49 Schraml P, Kononen J, Bubendorf L, et al. Tissue microarrays for gene amplification surveys in many different tumor types. Clin Cancer Res 1999;5: 1966-1975.

50 Al-Kuraya K, Schraml P, Torhorst J, et al. Prognostic relevance of gene amplifications and coamplifications in breast cancer. Cancer Res 2004;64:8534-8540.

51 Press MF, Sauter G, Bernstein L, et al. Diagnostic evaluation of HER-2 as a molecular target: an assessment of accuracy and reproducibility of laboratory testing in large, prospective, randomized clinical trials. Clin Cancer Res 2005;11:6598-6607.

52 Tapia C, Schraml P, Simon R, et al. HER2 analysis in breast cancer: reduced immunoreactivity in FISH non-informative cancer biopsies. Int J Oncol 2004;25: 1551-1557.

53 Mirlacher M, Kasper M, Storz M, et al. Influence of slide aging on results of translational research studies using immunohistochemistry. Mod Pathol 2004;17: 1414-1420.

54 Roche PC, Suman VJ, Jenkins RB, et al. Concordance between local and central laboratory HER2 testing in the breast intergroup trial N9831. J Natl Cancer Inst 2002;94:855-857. 
55 Haque AK, Syed S, Lele SM, et al. Immunohistochemical study of thyroid transcription factor-1 and HER2/ neu in non-small cell lung cancer: strong thyroid transcription factor-1 expression predicts better survival. Appl Immunohistochem Mol Morphol 2002;10: 103-109.

56 Nakamura H, Saji H, Ogata A, et al. Correlation between encoded protein overexpression and copy number of the HER2 gene with survival in non-small cell lung cancer. Int J Cancer 2003;103:61-66.

57 Hirsch FR, Franklin WA, Veve R, et al. HER2/neu expression in malignant lung tumors. Semin Oncol 2002;29:51-58.

58 Onn A, Correa AM, Gilcrease M, et al. Synchronous overexpression of epidermal growth factor receptor and HER2-neu protein is a predictor of poor outcome in patients with stage I non-small cell lung cancer. Clin Cancer Res 2004;10:136-143.

59 Koynova DK, Tsenova VS, Jankova RS, et al. Tissue microarray analysis of EGFR and HER2 oncogene copy number alterations in squamous cell carcinoma of the larynx. J Cancer Res Clin Oncol 2005;131: 199-203.

60 Khan AJ, King BL, Smith BD, et al. Characterization of the HER-2/neu oncogene by immunohistochemical and fluorescence in situ hybridization analysis in oral and oropharyngeal squamous cell carcinoma. Clin Cancer Res 2002;8:540-548.

61 Maubec E, Duvillard P, Velasco V, et al. Immunohistochemical analysis of EGFR and HER-2 in patients with metastatic squamous cell carcinoma of the skin. Anticancer Res 2005;25:1205-1210.

62 Chavez-Blanco A, Perez-Sanchez V, Gonzalez-Fierro A, et al. HER2 expression in cervical cancer as a potential therapeutic target. BMC Cancer 2004;4:59.

63 Kohlberger P, Edwards L, Hacker NF. Microinvasive squamous cell carcinoma of the cervix: immunohistochemically detected prognostic factors in a case with poor clinical outcome. Gynecol Oncol 2003;90: 443-445. 